\title{
Review: The Origin of Life Patterns-in the Natural Inclusion of Space in Flux
}

\author{
Louie J. N. Gardiner ${ }^{1,2}$
}

Received: 8 December 2017 / Revised: 7 February 2018 / Accepted: 9 February 2018 /

Published online: 2 March 2018

(C) The Author(s) 2018. This article is an open access publication

\begin{abstract}
Inclusionality

The space between defines the place of immateriality.

The thing you see is no such thing, as no such thing can be.

That which we see in time in space is concentrating energy

that flows in form in place through space, informing receptivity.

For space imbues; embraces all without exclusivity.

This grace-ful flow is nature's way, it's called inclusionality.

(C) Louie J N Gardiner 23rd June 2017.

This review stands as a metalogue (Bateson 1972:12) of Alan Rayner's principle of Natural Inclusion. As such, it not only offers a reflective commentary of the book but includes a reflexive account of what has been evoked and invoked in me, on my reading of it.
\end{abstract}

Keywords Metalogue - Natural inclusion - Unnatural exclusion - Inclusionality · Abstraction · State-waves · Bateson · Flow-form · Receptive space · Informative presence · Responsive energy Flux

\section{Reflexive Review}

As a doctoral candidate undertaking a trans-disciplinary inquiry into what it means to work systemically with individuals, I have covered quite some territory. My first year was

Louie J. N. Gardiner

louie.gardiner@potent6.co.uk

1 Doctoral Candidacy-HUBS, University of Hull, Hull HU6 7RX, UK

2 Edinburgh, UK 
challenging, not least because what I was reading in my academic realms did not appear to sit with my experience of living, working and playing with the folk around me. So much in the literature pointed to reductionism and linear thinking. This seemed at odds with the paradigm in which I was operating. In the late 1990s, I found myself drawn to the insights and principles arising from complexity and system sciences as, on the face of it, they seemed more attuned to my experience of reality. On re-entering the academy in 2014, I saw that academics in these new disciplines appeared not to be challenging nor re-defining the conventions that constrained them. Academic expectations, it seems, still proscribe a form and process which is recognisably derived from traditional (so-called objective) scientific experimentation (Popper 1934 (1959)). Even disciplines that do not sit in this space find themselves trapped by what a good academic paper or doctoral thesis looks like. I wanted to run for the hills - an urge that abated when, finally, I began to find voices from the edges who offered hope.

Bateson (1972; 1979; Bateson and Bateson 1987) was my first guideline. He introduced me to the notion of metalogue. This struck a deep resonance, and yet, there was something else I was groping for - a way that would enable me to articulate content in a form and process that was internally coherent. I was reaching for a metalogically coherent way to convey what was calling to be expressed through me. I found nothing in the literature that could help me, and instead crafted my own term: state-wave. Once I landed this as a concept, my thesis writing began to flow, matching my research process: a dance, interweaving ways of being, becoming, sensing, co-creating, sharing. Thus, I and my research flow onto the page in four different state-waves: Intellectual-Theoretic; Aesthetic-Poetic; Visual-Kinaesthetic; Navigator-Narrator (Gardiner, pending PhD completion). My Aesthetic-Poetic is most strongly in evidence in this paper. I introduce her thus:

[she] plays her part through personal poetry and prose; introduces word tapestries that weave narratives, musings, paradoxes and insights. I surrender myself to engaging in her non-rational, literary forms, which are variously reflective, reflexive, ${ }^{1}$ personal, emotional, lyrical and metaphorical. When she shows up, you may get a sense of the river being wide, spacious; its flow slow, gentle, rhythmic - giving space to what is calling to be revealed; or in contrast, wild, tumultuous, chaotic, messy. She speaks up when there is something needing expression or a tension needing to be released, which cannot easily be conveyed through other state-waves (Gardiner, $\mathrm{PhD}$ pending).

I thought I was alone-and then I came across my second guide-line: Alan Rayner using the term 'flow-form' and setting out his ideas on 'inclusionality'-Natural Inclusion. I was so excited. Finally, it seemed I had come across someone who was using something akin to 'state-wave'. He wrote of receptive space and responsive energy which chimed with my experience in life and in my writing process. I knew I had to talk to him. Our first connection was for me, like finding a kindred-spirit. We resonated on so many levels, such as our relationship with darkness (Rayner 2017b:1819)_experiencing it as a safe, restorative, regenerative space and not a fear-filled place where monsters of the imagination hide; and the notion of life being a dance, a dynamical, eternal state of flow (Rayner 2017b:80-84). It is unsurprising to me-given these connections and resonances - that my Aesthetic-Poetic was the first to attune to Alan's principle of Natural Inclusion which he first expressed as 'inclusionality'. My Aesthetic-Poetic grasped the gestalt and gifted me this synthesis of his proposition:

${ }^{1}$ The distinctions I make: 'reflective': past-oriented; and 'self-reflexive': present-to-immediate-future-oriented 


\section{Inclusionality}

The space between defines the place of immateriality.

The thing you see is no such thing, as no such thing can be.

That which we see in time in space is concentrating energy

that flows in form in place through space, informing receptivity.

For space imbues; embraces all without exclusivity.

This grace-ful flow is nature's way, it's called inclusionality. ${ }^{2}$

(C) Louie J N Gardiner 23rd June 2017

I voraciously read Alan's thinking on Natural Inclusion in previous articles (Rayner 2003, 2004; Rayner and Jarvilehto 2008; Shakunle and Rayner 2009; Rayner 2011, 2017a, b) and this, his most recent book. I did not always cognitively comprehend his forays into mathematics and physics, yet I sensed how deeply my embodied knowing seemed to 'get it'. He was helping me to express my living reality infinitely more coherently.

In The Origin of Life Patterns, Alan shares personally about his early experiences which so shaped his thinking and being in the world. To my astonishment, I found more synchronicities and deep resonances: we are both children born of Africa - our first contact with the earth being African soil; both being uprooted in formative years and translocated to an alien land (UK) whose cultural context did not match what we had already come to know. This dissonance served as an affront and a seemingly interminable constraint to life. Like Alan, I had a troubled start in the UK that set me apart from my peers. This set the scene for my life thereafter - trying to make sense of life and find my way to be a part of it. I found his willingness to share personally — which he does at the outset - a compelling and inviting way to open me up to what was to come. In this way, he demonstrates that even through static phrases on a page, we are in relationship. He is a real human being living a life, crafting these words, sharing his thoughts and I am there receiving and now writing about what has come to and through me. Beyond the simple words and the content they convey, we are a living expression of what this book is about: the flow of responsive energy into and between receptive space in place.

Alan's book is tiny-barely 100 pages and yet its import is, in my view, mighty. Through pictures, poetry, and first, second and third person exchange, he takes us on a journey through nature's places and spaces to help us see what he sees, to enable us to know what he has come to know. His life's learning is synthesised into something profoundly simply yet groundbreaking. He dismantles the fallacies that support man's propensities for abstracting life from life and brings us back to what is before, within and around us, and to what IS us. He opens a radically new way to see, understand and engage with life as it is, operating on what, arguably, is its most basic principle:

for any form to come into being, there have to be at least two basic kinds of presence in Nature: a motionless, receptive presence (i.e. a form-receiving presence analogous to empty canvas) and an intrinsically mobile, informative presence (i.e. a form-giving presence, analogous to fluid paint).... Moreover these two kinds of presence must include each other.... In the most fundamental and universal sense, applicable literally to everywhere, these two natural presences are experienced in the feeling of emptiness

\footnotetext{
${ }^{2}$ Inclusionality: Alan Rayner (2003, 2004) first used this term to illuminate nature's patterning which, he says, is in direct contrast to Darwinian thinking. It also challenges assumptions that pervade mathematics and physics. Alan now uses the term 'Natural Inclusion'.
} 
that we call 'space'... and enlivening flux that we call 'energy'. Energy paints the variety of the natural world on an intangible canvas of receptive space (Rayner 2017b:25)

In his very conceptualisation of Natural Inclusion as the "mutual inclusion of receptive space and informative flux" (Rayner 2017a, b:26) where...

energy and space combine into local material bodies as flow-forms... 'energised beings' whose association, disassociation and exchanges of energy with and from one another is the source of evolutionary variety across all scales of natural organisation, including biological organisation ... (Rayner 2017b:26)

...Alan is challenging the very ground on which mathematics, physics and natural sciences are founded. How? Because he shows that we cannot abstract space from ourselves (we, who are 'matter' created by concentrating energy flows in place in space), any more than we can abstract ourselves from space: "for space imbues; embraces all without exclusivity" (Gardiner, poem above)! As soon as we let this in - everything begins to change. Not least, the realisation that there really is 'no outside' and that we all are truly in and of the universal hole - receptive space.

This book and its insights are made possible by Rayner's evident extensive knowledge of the natural world and his willingness to go where others might not dare to tread. The dominions of so-called rational sciences are held in such high regard by those who claim their bases of knowledge as absolute truths. This illusory net, which is invisible to most, reaches into all aspects of our thinking. It affects how we talk and seeps into our daily lives - in what we do, and how we do it. To enter that dominion and then presume to challenge the very ground its existence depends upon, could be seen as an act of daring or outright stupidity. To me it is an act of bold service by one who sees what most of us have yet to come to see; it is a gift we did not ask for and did not know we needed.

He re-defines 'natural science' which thus far has been shaped by Darwin's (1861) assertions of 'natural selection'. Perhaps this now would be more aptly described as 'unnatural exclusion'? Rayner shows us the myriad and universal ways in which nature's principle repeatedly reveals itself to be one of Natural Inclusion. This is it. Simple. Elegant. Undeniable. And if that were not enough, Rayner extends his exploration into psycho-social realms of self-identity, beliefs, conflicts and more. In so doing, he illuminates the ensuing tragedies and traumas that manifest while ever we hold on to a belief that unnatural exclusion is nature's way. It is not.

Through his book, Rayner is equipping us to return to what is natural, beyond abstraction. If we risk following where he leads, we might well find ourselves returning joyfully to life's universal, eternal flow.

Beyond Abstraction

Beyond abstraction:

lies the surge that spills and moves this One to act;

tips the urge that moves then stills the tears that trace

in rivulets across the face that can't resist

the myth that certainty exists.

Beyond abstraction -

Lies. The calculating mind that drives us to distraction -

full of shards and knives that pierce and slice 
all sense of what is whole and true and meant, to bits that have no rhythm, rhyme nor consequence.

Beyond abstraction

lies a life in raw kaleidoscopic specks

that float and shift in patterned drifts, adrift

in senseless seas of wretched fear that this

is all there is, beyond our mental mortal rifts.

Beyond abstraction?

Lies? Or simply fictions told of lives, for want

of meaning more than facts and feelings tell? We claim

as truths our ways are best - as proof of life and worth

beyond the bones and skin of immaterial selves!

Beyond abstraction,

Bliss behoves the one who puts in place

her rational grip beside each part, so all can

move and sway in co-created patterned play -

such artistry between, is Symmathesic Agency.

Beyond abstraction:

Bliss becomes, when finally, we see what is, is not.

Beyond abstraction:

Bliss belies the lie that change comes on command.

Beyond abstraction:

Bliss beholds - as tension tips - the dance as it unfolds.

Beyond abstraction:

Bliss befalls - when flow begins to flow between receptive holes.

(C) Louie J N Gardiner $15^{\text {th }}$ October 2016

Open Access This article is distributed under the terms of the Creative Commons Attribution 4.0 International License (http://creativecommons.org/licenses/by/4.0/), which permits unrestricted use, distribution, and reproduction in any medium, provided you give appropriate credit to the original author(s) and the source, provide a link to the Creative Commons license, and indicate if changes were made.

\section{References}

Bateson, G. (1972). Steps to an ecology of mind: Collected essays in anthropology, psychiatry, evolution, and epistemology (1st ed.). Chicago: University of Chicago Press.

Bateson, G. (1979). Mind and nature: a necessary unity. Creskill: Hampton Press Inc..

Bateson, G. \& Bateson, M. C. (1987). Angels fear: an investigation into the nature and meaning of the sacred. London: Rider. 
Darwin, C. (1861) On the origin of the species by means of natural selection or the Preservation of favoured races in the struggle for life. New York: D Appleton and Company.

Popper, K. (1934). The Logic of Scientific Discovery 1959. Google Scholar, 59. London: Hutchinson.

Rayner (2003). Winnett, A., Warhurst, A. (eds). In: Towards an Environmental Research Agenda: A Second Selection of Papers. Basingstoke: Palgrave Macmillan Springer.

Rayner, A. D. M. (2004). Inclusionality and the role of place, space and dynamic boundaries in evolutionary processes. Philosophica, 73, 51-70.

Rayner, A. D. M. (2011). NatureScope [eBook]. Winchester: John Hunt Publishing.

Rayner, A. D. M. (2017a) Natural flow-form: a mutual inclusion of strength and weakness (Article). Available online: https://www.bestthinking.com/articles/science/biology_and_nature/natural-flow-form-a-mutualinclusion-of-strength-and-weakness [Accessed].

Rayner, A. D. M. (2017b). The origin of life patterns: in the natural inclusion of space in flux. Berlin: Springer.

Rayner, A. D. M., \& Jarvilehto, T. (2008). From dichotomy to inclusionality: a transformational understanding of organism-environment relationships and the evolution of human consciousness. Transfigural Mathematics, $1(2), 67-82$.

Shakunle, L. O., \& Rayner, A. D. M. (2009). Transfigural foundations for a new physics of natural diversityvariable inclusion of gravitational space in electromagnetic flow-form. Journal of Transfigural Mathematics, 1(2), 109-122. 